\title{
A Physically-Based Model for Urban Fire Spread
}

\author{
HIMOTO Keisuke and TANAKA Takeyoshi \\ Disaster Prevention Research Institute, Kyoto University \\ Gokasho, Uji, Kyoto 611-0011, Japan
}

\begin{abstract}
An attempt is made to develop a physically-based model for simulating urban fire spread. In the model, urban fire is regarded as an ensemble of multiple building fires. The model consists of two sub-models, i.e. the model to predict the building fire behavior under the exposure of heating from other building fires and the model to predict the thermal environment caused by building fires. The building fire model is based on single zone method, applying control volumes to compartments in a building. When the external heating, whether it is from the same building or from other buildings, exceeds the critical heat flux, the fire load in the compartment ignites and burns. For the thermal environment model, thermal radiation and fire-induced plume are considered as the factors of building-to-building fire spread. The model is applied to a fictitious urban district where 49 multi-room buildings are arrayed in a simple configuration.
\end{abstract}

KEYWORDS: fire spread, urban fire, post-earthquake fire, zone model

\section{INTRODUCTION}

Post-earthquake fire is one of the important factors enlarging the damage of a severe earthquake. Having experienced 1995 Kobe Earthquake, the importance of mitigating losses due to post-earthquake fires was recognized anew. To explore the effective measures for reducing the loss, it is indispensable to have a means to rationally predict the behavior of post-earthquake fires.

There exist several models for the purpose of simulating the fire spread in urban district. The earliest of these models was developed by Hamada [1], which expressed fire spread rate as a function of wind velocity and average building-to-building distance. The rate coefficients were derived empirically from the investigative report of urban fire incidents in the past. Horiuchi extended the Hamada's model considering the fire resistance performance of houses [2]. Tokyo Fire Station reconstructed the Hamada's empirical model and renewed the coefficients from the recent fire incidents data in Tokyo [3]. Itoigawa et al. reformed the Tokyo Fire Station's model considering the building-tobuilding fire spread as a probability process [4].

These models have been utilized by numerous local governments and have contributed to their improvements in loss mitigation systems. However, the models developed so far are empirical or probabilistic models. In consequence, they inevitably involve empirical parameters, which may lose validity in time as the conditions of urban environment such as fire protection performance of individual buildings or urban structure in general may change.

In such circumstances, the authors took a new approach to develop a model, i.e. a physically-based model where urban fire is regarded as an ensemble of numerous 
individual fires and the urban fire spread could be predicted by integrating the simulation of these individual fires. The notable difference between a building fire involved in urban fire and an independent building fire, is that the former is under the thermal influence from other fires, such as radiation and fire induced flow. Thus, the model consists of two sub-models, i.e. building fire model and thermal environment model.

\section{MODELLING}

Fig.1 illustrates the conceptual diagram of the urban fire spread model. In this study, single zone method is applied to describe fire behaviors inside buildings composed of multiple rooms. Fire spreads from one room to another inside a building due to the transport of heat and excess fuels generated in the fire compartments. At the same time, the generated heat is transferred to adjacent buildings by radiation and convection of fire-induced plume to elevate ambient temperature. If the combustibles inside the building ignite and begin to burn due to the external heating, the building then becomes a new heat source to other buildings.

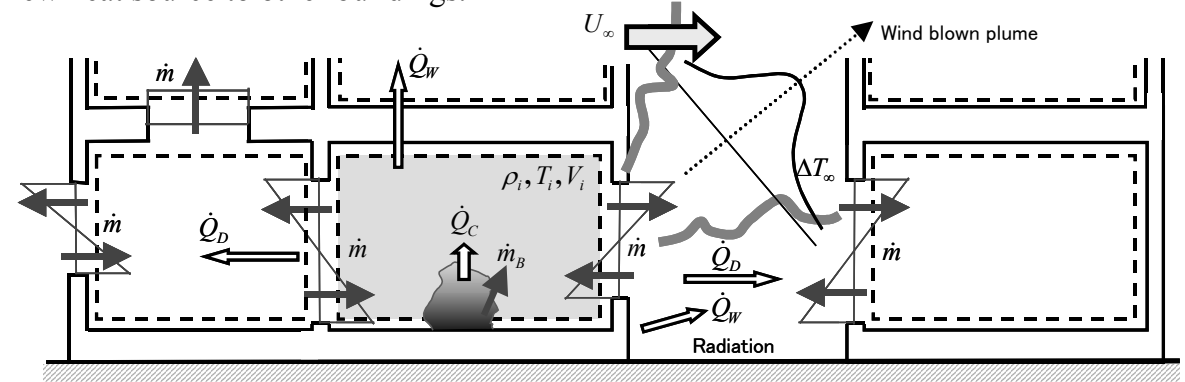

Fig. 1: Urban fire spread model

\section{2-1 Building Fire Model under External Heat Exposure}

\section{2-1-1 Governing equations for an arbitrary compartment- $i$}

The compartment gas is assumed black from the beginning for simplicity. Referring to Fig. 1, the conservation equations for an arbitrary compartment- $i$ are described as follows:

Mass:

$$
\frac{d}{d t}\left(\rho_{i} V_{i}\right)=\sum_{j}\left(\dot{m}_{j i}-\dot{m}_{i j}\right)+\dot{m}_{B, i}
$$

Energy: $\quad \frac{d}{d t}\left(c_{P} \rho_{i} T_{i} V_{i}\right)=\dot{Q}_{C, i}-\sum_{j}\left(\dot{Q}_{W, i j}+\dot{Q}_{D, i j}\right)$

$$
+\sum_{j}\left(c_{P} \dot{m}_{j i} T_{j}-c_{P} \dot{m}_{i j} T_{i}\right)+\left(c_{P} T_{P}-L_{P}\right) \dot{m}_{B, i}
$$

where $\rho$ is the density, $V$ is the volume, $\dot{m}$ is the mass flow rate through opening, $\dot{m}_{B}$ is the mass burning rate, $c_{P}$ is the specific heat, $T$ is the temperature, $\dot{Q}_{C}$ is the HRR and $\dot{Q}_{W}$ and $\dot{Q}_{D}$ are the heat loss through wall and opening, respectively. Note however, that $\dot{Q}_{W}$ and $\dot{Q}_{D}$ not only express the heat transfer within the building but also from other buildings on fire. $T_{P}$ and $L_{P}$ are the temperature and the heat of gasification of fuel, respectively. $\Sigma$ denotes to take the summation of the relevant values with respect to all the boundary elements. The subscripts $j$ refers to the adjacent compartment or outdoor space to $i$ and $i j$ indicates the origin and the destination of mass/heat transfer.

Also for the chemical species, 
Oxygen:

$$
\frac{d}{d t}\left(\rho_{i} V_{i} Y_{O, i}\right)=\sum_{j}\left(\dot{m}_{j i} Y_{O, j}-\dot{m}_{i j} Y_{O, i}\right)-\dot{\Gamma}_{O, i},
$$

Combustible gas: $\frac{d}{d t}\left(\rho_{i} V_{i} Y_{F, i}\right)=\sum_{j}\left(\dot{m}_{j i} Y_{F, j}-\dot{m}_{i j} Y_{F, i}\right)+\dot{m}_{B, i}-\dot{\Gamma}_{F, i}$

where $Y_{O}$ and $Y_{F}$ are the mass fraction of oxygen and combustible gas, respectively, which are associated with the computation of HRR. $\dot{\Gamma}_{O}$ and $\dot{\Gamma}_{F}$ are the consumption rate of oxygen and combustible gas, respectively.

The compartment gas is regarded as ideal and the equation of ideal gas state is modified considering the atmospheric pressure. That is:

$$
\rho_{i} T_{i}=353\left[\mathrm{~kg} \cdot \mathrm{K} \cdot \mathrm{m}^{-3}\right] .
$$

\section{2-2-2 Combustion of Fire Load}

\section{Mass burning rate}

It is assumed that the fire load in the compartment burns in proportion to the net incident heat flux to the fuel, provided the heat flux exceeds the critical heat flux of ignition.

$$
\dot{m}_{B}=\frac{\phi\left(\dot{q}_{F}^{\prime \prime}-\dot{q}_{c r}^{\prime \prime}\right)}{L_{P}} A_{B}
$$

where $\phi$ is the heat transfer coefficient associated with charring, $\dot{q}_{F}^{\prime \prime}$ is the incident heat flux to the fuel surface, $\dot{q}_{c r}^{\prime \prime}$ is the heat flux leaving from the fuel surface which is at critical temperature of pyrolysis $T_{P}$ and $A_{B}$ is the burning area of fuel bed.

As illustrated in Fig.2(a), compartment gas (heat flux: $\dot{q}_{i, R}^{\prime \prime}$ ) and flame (heat flux: $\dot{q}_{\text {flame }}^{\prime \prime}$ ) are considered as the heat sources to the fuel bed. However, not all of $\dot{q}_{i, R}^{\prime \prime}$ will reach to the fuel bed as the flame will absorb part of it (Fig.2(b)).

The overall incident heat flux $\dot{q}_{F}^{\prime \prime}$ is given by introducing following assumptions: (i) compartment gas and fuel bed are separated by the flame sheet (HRR: $\dot{Q}_{C}$ ); (ii) the flame is thermally thin i.e. considering the mean beam length of the flame is thick enough for emissivity $\varepsilon_{\text {flame }} \approx 1[-]$; (iii) $\dot{q}_{i, R}^{\prime \prime}$ is absorbed by the flame and; (iv) the flame sheet releases the heat flux of $\dot{q}_{F}^{\prime \prime}$. Thus, the radiation heat flux from the compartment gas affects the temperature rise of the flame sheet and indirectly heats up the fuel (Fig.2(c)). When compartment gas temperature is low and no heat flux from the compartment gas is assumed ( $\dot{q}_{i, R}^{\prime \prime} \cong 0$ ), the energy conservation for the flame sheet is given as:

$$
\dot{Q}_{C}+\dot{q}_{c r}^{\prime \prime} A_{\text {flame }}=\dot{q}_{\text {flame }}^{\prime \prime} A_{\text {flame }}
$$

where $A_{\text {flame }}$ is the flame sheet surface area. On the other hand, when the compartment gas temperature elevates and the heat flux $\dot{q}_{i, R}^{\prime \prime}$ becomes unnegligible:

$$
\dot{Q}_{C}+\dot{q}_{c r}^{\prime \prime} A_{\text {flame }}+\dot{q}_{i, R}^{\prime \prime} A_{\text {flame }}=2 \dot{q}_{F}^{\prime \prime} A_{\text {flame }} .
$$

From Eqs.(7) and (8) yield the following incident heat flux to the fuel surface:

$$
\dot{q}_{F}^{\prime \prime}=\dot{q}_{\text {flame }}^{\prime \prime}+1 / 2 \dot{q}_{i, R}^{\prime \prime}
$$

in which $\dot{q}_{\text {flame }}^{\prime \prime}$ and $\dot{q}_{i, R}^{\prime \prime}$ are given as:

$$
\dot{q}_{\text {flame }}^{\prime \prime}=\varepsilon_{F} \varepsilon_{\text {flame }} \sigma T_{\text {flame }}^{4}+h_{F} T_{\text {famel }} \text { and } \quad \dot{q}_{i, R}^{\prime \prime}=\varepsilon_{F} \sigma T_{i}^{4} .
$$

And critical heat flux $\dot{q}_{c r}^{\prime \prime}$ is given as:

$$
\dot{q}_{c r}^{\prime \prime}=\varepsilon_{\text {flame }} \varepsilon_{F} \sigma T_{P}^{4}+h_{F} T_{P} .
$$





(a) whole view

(b) heat transfer near fuel surface

(c) heat flux model

Fig. 2: Heat flux to the fuel bed

\section{Spread of fire to adjacent compartment through opening}

In order to predict the fire spread from one room to another inside the building or to adjacent buildings, it is important to take into account the local effect of heat transfer, since the fire spread begins with the ignition of combustibles around openings where combustibles are more severely exposed to the heat from fire.

It is assumed that the ignition of the fuel bed occurs when the incident heat flux through opening $\dot{q}_{D}^{\prime \prime}$ from adjacent space exceeds the critical heat flux of gasification $\dot{q}_{c r}^{\prime \prime}$ $\left(\dot{q}_{D}^{\prime \prime}>\dot{q}_{c r}^{\prime \prime}\right)$. The area of combustibles receiving direct heat through openings $A_{B, 0}$ is regarded as follows:

$$
A_{B, 0}=A_{F}\left(A_{D} / A_{\text {total }}\right)
$$

where $A_{F}, A_{D}$ and $A_{\text {total }}$ are the total surface area of the fuel bed, the area of opening and the total surface area of the compartment, respectively.

\section{Flame spread in compartment}

Once the fuel has ignited, the burning area $A_{B}$ increases due to the incident heat flux from the flame itself $\dot{q}_{\text {flame }}^{\prime \prime}$ and from the compartment gas $\dot{q}_{i, R}^{\prime \prime}$. Following Quintiere, the flame spread rate $v_{\text {flame }}$ is given by [5]:

$$
v_{\text {flame }}=\left[C_{\text {flame }}\left(\dot{q}_{c r}^{\prime \prime}-\dot{q}_{i, R}^{\prime \prime}\right)\right]^{-2}
$$

where $C_{\text {flame }}$ is the rate coefficient. $\dot{q}_{\text {flame }}^{\prime \prime}$ is not apparent in the expression but it is assumed as a material dependent property and included in $C_{\text {flame }}$. The experiment by Quintiere was for the lateral flame spread, so here, the coefficient $C_{\text {flame }}$ will be modified in order to adapt to the realistic fire load configuration in compartments.

Idealizing the burning area $A_{B}$ as a circle, the increase of the area $d A_{B} / d t$ is given by:

$$
d A_{B} / d t=2 \pi r_{B} \cdot v_{\text {flame }}
$$

where $\pi$ is the circumstance ratio, $r_{B}$ is the radius of $A_{B}$, which is given by $\left(A_{B} / \pi\right)^{1 / 2}$.

\section{Heat release rate}

The gasified fuel released from the combustibles burns and generates heat. In a compartment fire, HRR is controlled by whichever the smaller rate of oxygen or combustible gas supplied. Hence the HRR $\dot{Q}_{C}$ for the compartment $i$ is given by:

$$
\dot{Q}_{C, i}=\min \left(\dot{Q}_{O, i}, \dot{Q}_{F, i}\right)
$$


in which $\dot{Q}_{O}$ and $\dot{Q}_{F}$ are given as:

$$
\dot{Q}_{O, i}=\Delta H_{O} \sum_{j} \dot{m}_{j i} Y_{O, j} \text { and } \dot{Q}_{F, i}=\Delta H_{F}\left(\dot{m}_{B, i}+\sum_{j} \dot{m}_{j i} Y_{F, j}\right)
$$

where $\dot{Q}_{O}$ and $\dot{Q}_{F}$ are the HRR when all of existing oxygen or combustible gas are consumed for combustion. The gasified fuel which take part in the combustion includes the fuels transferred by ventilation from adjacent compartment as well. Using the HRR obtained from Eq.(15), the consumption rates of chemical species $\dot{\Gamma}_{O, i}$ and $\dot{\Gamma}_{F, i}$ are given as:

$$
\dot{\Gamma}_{O, i}=\dot{Q}_{C, i} / \Delta H_{O} \quad \text { and } \quad \dot{\Gamma}_{F, i}=\dot{Q}_{C, i} / \Delta H_{F} .
$$

\section{2-1-3 Heat Transfer at Compartment Boundary}

Walls and openings are considered as the passages of heat transfer at the compartment boundary as shown in Fig.3, in which the boundary is separating spaces $i$ and $j$.

\section{Heat transfer through wall}

Distinct from independent building fires, external heating from other fires is considered for building fires in urban fire environment. According to the configuration in Fig.3, where $i$ is considered as an indoor or outdoor space and $j$ is an indoor space, the heat transfer at $i$-side of the wall surface is given by:

$$
\dot{Q}_{W, i j}=\left(\dot{q}_{W, i j}^{\prime \prime}-\dot{q}_{W, j i}^{\prime \prime}\right) A_{W}
$$

in which the heat flux at wall surface $\dot{q}_{W}^{\prime \prime}$ is given by:

$$
\begin{aligned}
& \left.\dot{q}_{W, i j}^{\prime \prime}=\varepsilon_{W} \mid\left(1-\sum \varphi_{R}\right) \sigma T_{i}^{4}+\sum \varphi_{R} \dot{q}_{R}^{\prime \prime}\right\rfloor+h_{W} T_{i} \\
& \dot{q}_{W, j i}^{\prime \prime}=\varepsilon_{W} \sigma T_{W}^{4}+h_{W} T_{W}
\end{aligned}
$$

where $A_{W}$ is the wall surface area and $T_{W}$ is the wall surface temperature. $\varphi_{R}$ is the configuration factor of an external heat source and $\dot{q}_{R}^{\prime \prime}$ is its radiant power. In the case $i$ represents the compartment inside the building, the configuration factor in Eq.(19) becomes $\varphi_{R}=0$ and Eq.(18) is reduced to be an usual heat transfer expression: $\dot{Q}_{W, i j}=\left[\varepsilon_{W} \sigma\left(T_{i}^{4}-T_{W}^{4}\right)+h_{W}\left(T_{i}-T_{W}\right)\right] A_{W}$. The surface temperatures of the wall $T_{W}$ is obtained numerically by solving the one-dimensional heat conduction equation with moisture content.

\section{Heat transfer through opening}

It is assumed that an opening is partially open and partially closed. Letting $r_{D}$ be the fraction of open area to the total opening area $A_{D}$, the heat transfer through the opening is calculated as:

$$
\dot{Q}_{D, i j}=\left[\left(1-r_{D}\right)\left(\dot{q}_{G, i j}^{\prime \prime}-\dot{q}_{G, j i}^{\prime \prime}\right)+r_{D}\left(\dot{q}_{D, i j}^{\prime \prime}-\dot{q}_{D, j i}^{\prime \prime}\right)\right] A_{D}
$$

where $\dot{q}_{G}^{\prime \prime}$ is the heat flux at closed part given by:

$$
\begin{aligned}
& \dot{q}_{G, i j}^{\prime \prime}=\varepsilon_{G}\left[\left(1-\sum \varphi_{R}\right) \sigma T_{i}^{4}+\sum \varphi_{R} \dot{q}_{R}^{\prime \prime}\right]+h_{G} T_{i} \\
& \dot{q}_{G, j i}^{\prime \prime}=\varepsilon_{G} \sigma T_{G}^{4}+h_{G} T_{G}
\end{aligned}
$$

and $\dot{q}_{D}^{\prime \prime}$ is the heat fluxes at open part given by:

$$
\dot{q}_{D, i j}^{\prime \prime}=\left(1-\sum \varphi_{R}\right) \sigma T_{i}^{4}+\sum \varphi_{R} \dot{q}_{R}^{\prime \prime}
$$




$$
\dot{q}_{D, j i}^{\prime \prime}=\sigma T_{j}^{4}
$$

where $T_{G}$ is the temperature of the opening material. In the current model, opening material is considered to be thermally thin and has a uniform temperature. Accordingly, $T_{G}$ is determined in order to satisfy the conservation equation of energy for the concerning material. In the event of fire, some opening elements break due to the heat exposure. Although the breaking of opening materials is more or less probabilistic, a simple model is employed such that the opening rate $r_{D}$ is assumed to be a linear function of the material temperature $T_{G}$. (For the case of window glass, temperature at which the breakage begins is $T_{G, c r} \cong 200\left[{ }^{\circ} \mathrm{C}\right]$ and linearly increase $r_{D}$ in the range of $\left.\Delta T_{G, c r} \cong 200\left[{ }^{\circ} C\right]\right)$.

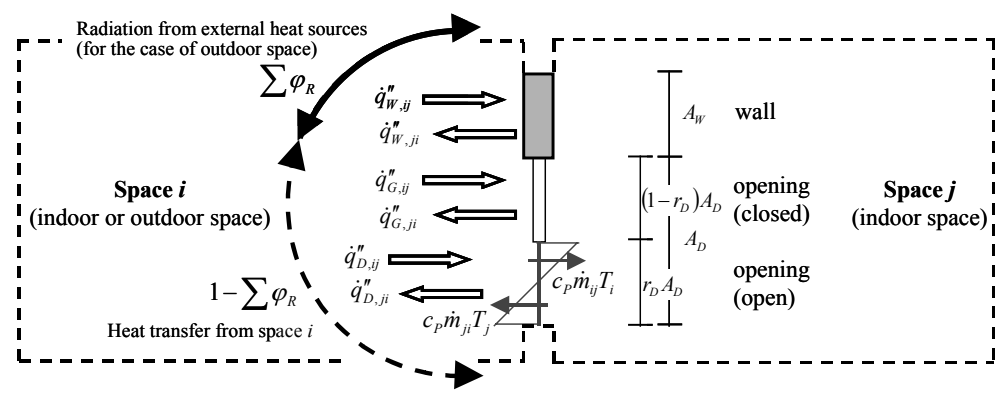

Fig. 3: Heat transfer at the boundary considering external heat sources

\section{2-1-4 Mass Transfer at Boundary}

The rates of opening flows are formulated as a function of pressure difference which is formed as the compartment temperature rises. Substituting Eq.(5) into Eq.(2) yields:

$$
\dot{Q}_{C, i}-\sum_{j}\left(\dot{Q}_{W, i j}+\dot{Q}_{D, i j}\right)+\sum_{j}\left(c_{P} \dot{m}_{j i} T_{j}-c_{P} \dot{m}_{i j} T_{i}\right)+\left(c_{P} T_{P}-L_{P}\right) \dot{m}_{B, i} \cong 0 \text {. }
$$

The mass flow rate at the opening is determined to satisfy this Eq.(23).

\section{2-2 External Thermal Environment Model}

Two factors of building-to-building fire spread, thermal radiation and fire induced plume, are modeled. Another principal factor, fire brand, is not dealt with in the current model.

\section{2-2-1 Thermal Radiation}

\section{Radiation heat flux}

Sources of building-to-building thermal radiation heat flux will be: (i) compartment gas and flame through openings $\dot{q}_{D, R}^{\prime \prime}$, (ii) heated exterior walls $\dot{q}_{W, R}^{\prime \prime}$ and (iii) ejected flames $\dot{q}_{\text {Eflame }}^{\prime \prime}$. For simplicity, these heat sources are regarded as a single heat source and its radiation heat flux $\dot{q}_{R}^{\prime \prime}$ is approximated as (Fig.4):

$$
\dot{q}_{R}^{\prime \prime}=\frac{\dot{q}_{D, R}^{\prime \prime} A_{D}+\dot{q}_{W, R}^{\prime \prime}\left(A_{W}-A_{E f l a m e}\right)+\dot{q}_{\text {Eflame }}^{\prime \prime} A_{\text {Eflame }}}{A_{D}+A_{W}}
$$

in which $\dot{q}_{D, R}^{\prime \prime}, \dot{q}_{W, R}^{\prime \prime}$ and $\dot{q}_{E f l a m e}^{\prime \prime}$ are given as:

$$
\dot{q}_{D, R}^{\prime \prime}=\sigma T_{i}^{4}, \quad \dot{q}_{W, R}^{\prime \prime}=\varepsilon_{W} \sigma T_{W}^{4} \text { and } \dot{q}_{E \text { flame }}^{\prime \prime}=\varepsilon_{\text {flame }} \sigma\left(T_{\infty}+\Delta T_{E f l a m e}\right)^{4}
$$

where $T_{\infty}$ is the ambient temperature, $\Delta T_{E f l a m e}$ is the temperature rise of ejected flame 
and $A_{\text {Efame }}$ is its area. The configuration factors between exterior walls $\varphi_{R}$ are substituted for the ones of respective heat sources to obtain the radiation heat flux $\varphi_{R} \dot{q}_{R}^{\prime \prime}$, which appears in Eqs.(19a), (21a) and(22a). $\varphi_{R}$ are computed numerically according to the unit-sphere method.



Fig. 4: Radiation heat flux from the building on fire

\section{Ejected flame}

To obtain $\dot{q}_{\text {Eflame }}^{\prime \prime}$ and $A_{\text {Eflame, }}$, the flame temperature rise $\Delta T_{\text {Eflame }}$ and its height $Z_{\text {Eflame }}$ are needed to be known. Yokoi derived the following dimensionless temperature $\Theta$ to quantify the temperature rise of the ejected flame at center-line [6]. We employ the following relation of $\Theta$ to obtain $\Delta T_{\text {Eflame }}$ and $Z_{\text {Eflame }}[7]$ :

$$
\frac{Z_{\text {Eflame }}}{r_{0}}= \begin{cases}1.05 \Theta^{-1} & (\Theta \leq 0.35) \\ \left(1.93 \times 10^{-3}\right) \Theta^{-7} & (\Theta>0.35)\end{cases}
$$

in which $\Theta$ is given as:

$$
\Theta=\frac{\Delta T_{\text {Eflame }}}{\left(\dot{Q}_{\text {Eflame }}^{2} T_{\infty} / C_{P}^{2} \rho^{2} g r_{o}^{5}\right)^{1 / 3}}
$$

where $r_{o}$ is the equivalent radius of the concerning opening given as $\left(A_{D} / \pi\right)^{1 / 2}$ and $\dot{Q}_{\text {Eflame }}$ is the apparent HRR of the ejected flame including the combustion of excess fuel which is given as:

$$
\dot{Q}_{\text {Eflame }}=c_{P} \dot{m}_{i j}\left(T_{i}-T_{\infty}\right)+\Delta H_{F}\left(\dot{m}_{i j} Y_{F, i}\right) .
$$

\section{2-2-2 Fire Induced Plume}

A plume originated from an opening is blown down by the wind and exposes the buildings in the downstream to the air at elevated temperature.

\section{Temperature rise at center-line}

Although the behaviors of vertical plume have been well studied [8], there is not sufficient data for the ones blown down by wind. Here, the results for vertical plumes are employed to evaluate the temperature rise at the center-line $\Delta T_{0}$, which is given by:

$$
\Delta T_{0}= \begin{cases}900 & \left(z / \dot{Q}_{C}^{2 / 5}<0.08\right) \\ 60\left(z / \dot{Q}_{C}^{2 / 5}\right)^{-1} & \left(0.08 \leq z / \dot{Q}_{C}^{2 / 5}<0.2\right) \\ 24\left(z / \dot{Q}_{C}^{2 / 5}\right)^{-5 / 3} & \left(0.2 \leq z / \dot{Q}_{C}^{2 / 5}\right)\end{cases}
$$

where $\Delta T_{0}$ is the temperature rise at center-line and $z$ is the distance above the center of a building. The HRR of the compartment fire $\dot{Q}_{C}$ is employed as the heat source. 


\section{Ambient temperature rise of downstream compartments}

For the current model, we assume the axisymmetricity of temperature profile is conserved despite of the effect of wind and urban configuration. In general, target buildings are located more or less remote from the center-line. The temperature rise at the downstream compartment is given as (Fig.5):

$$
\Delta T(r) / \Delta T_{0}=\exp \left[-\beta\left(r / l_{t}\right)^{2}\right\rfloor
$$

where $r$ is the radial distance from center-line to the concerning compartment. $l_{t}$ is the Gaussian half widths and $\beta$ is the ratio of temperature half widths to velocity half widths. Following Yokoi, the rise angle $\theta$ of the plume center-line under the wind of velocity $U_{\infty}$ is given as [9]:

$$
\tan \theta=0.1\left[U_{\infty} /\left(\dot{Q}^{\prime} g / \rho_{\infty} C_{P} T_{\infty}\right)^{1 / 3}\right]^{-3 / 4}
$$

where $\dot{Q}^{\prime}$ is the HRR per unit length defined as $\dot{Q}^{\prime}=\dot{Q}_{C} / \sqrt{A_{\text {floor }}}$.

\section{Mixing effect of plumes}

In urban fires, plural fires occur simultaneously and buildings in the downstream are put under the interacting influence of these multiple plumes. However, we do not consider the complicated behaviors of such plumes, but evaluate the temperature rise by overlaying the temperature rises due to individual fire plumes, which is given by [10]:

$$
\Delta T=\left[\sum_{i=1}^{N}\left(\Delta T_{i}\right)^{3 / 2}\right]^{2 / 3}
$$

where $\Delta T$ is the overall temperature rise, $\Delta T_{i}$ is the temperature rise of individual plume- $i$ given by Eq.(30) and $N$ is the number of plumes.

The ambient temperature rise will appear as the temperature rise of $T_{i}$ in Eqs.(19a), (21a) and (22a) to heat up the downstream buildings.

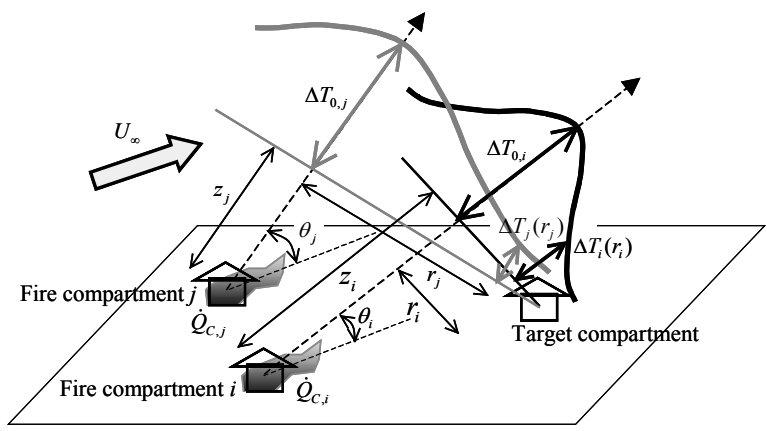

Fig. 5: Blown down fire-induced plumes

\section{Numerical Simulation}

\section{3-1 Conditions}

The model was applied to an ideal urban district where 49 identical buildings were arrayed in a uniform distance of $3[\mathrm{~m}]$. The configuration of the buildings are shown in Fig. 6(a) and (b). The buildings were assumed ALC(Autoclaved light weight concrete: Table 1) houses composed of 10 rooms. The rooms are numbered as shown in Fig. 6(a) 
for identification.

The openings on the exterior walls except for the ones on East/West side of the buildings, which $1 / 10$ of the area were open, were closed. On the other hand, all the openings in the internal partitions were open. Window glass was assumed for the material.

Wood was assumed as the fire load and its properties are shown in Table 2. The surface area of the fuel were given by $A_{F}=0.61 w^{l / 3} A_{\text {flor }}$, which is based on the investigation [11]. Initially, the ambient temperature was $593[\mathrm{~K}]\left(20\left[{ }^{\circ} \mathrm{C}\right]\right)$ and wind was blowing from south to north. The simulation was carried out at two different wind velocities, which were 0.0 and $5.0\left[\mathrm{~m} \cdot \mathrm{s}^{-1}\right]$.

The surface area of $0.01\left[\mathrm{~m}^{2}\right]$ flame was placed in the compartment No.2 of the building just in the center of the buildings as the ignition source.
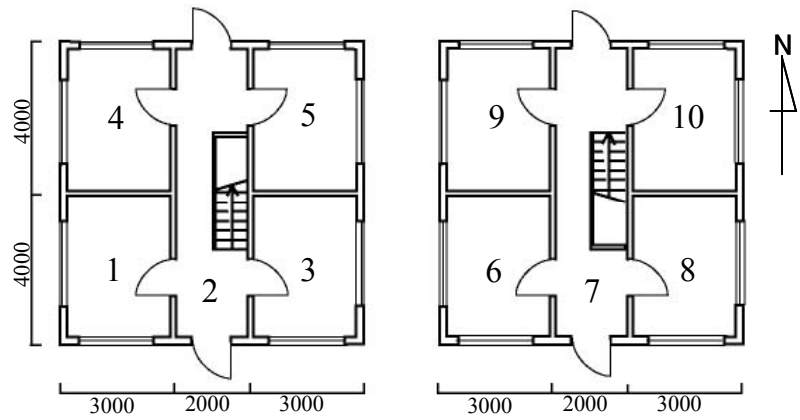

unit: $[\mathrm{mm}]$

Fig. 6(a): Building plan (left: 1st floor, right: 2nd floor)


Fig. 6(b): Building elevation (left: North/South, right: West/East)

Table 1: Properties of ALC

\begin{tabular}{ccccc}
\hline $\begin{array}{c}\text { thermal conductivity } \\
{\left[\mathrm{kW} \cdot \mathrm{m}^{-1} \cdot \mathrm{K}^{-1}\right]}\end{array}$ & $\begin{array}{c}\text { density } \\
{\left[\mathrm{kg} \cdot \mathrm{m}^{-3}\right]}\end{array}$ & $\begin{array}{c}\text { heat capacity } \\
{\left[\mathrm{kJ} \cdot \mathrm{kg}^{-1} \cdot \mathrm{K}^{-1}\right]}\end{array}$ & $\begin{array}{c}\text { thickness } \\
{[\mathrm{m}]}\end{array}$ & $\begin{array}{c}\text { moisture content } \\
{[\%]}\end{array}$ \\
\hline $0.15 \times 10^{-3}$ & 600 & 1.1 & 0.125 & 5.0 \\
\hline
\end{tabular}

Table 2: Properties of fire load (wood)

\begin{tabular}{cccc} 
heat of combustion & heat of gasification \\
$\Delta H_{F}\left[\mathrm{~kJ} \cdot \mathrm{kg}^{-1}\right]$ & $L_{P}\left[\mathrm{~kJ} \cdot \mathrm{kg}^{-1}\right]$ & $\begin{array}{c}\text { pyrolysis temp. } \\
T_{P}[\mathrm{~K}]\end{array}$ & $\begin{array}{c}\text { distribution density } \\
w\left[\mathrm{~kg} \cdot \mathrm{m}^{-2}\right]\end{array}$ \\
\hline 17000 & 1800 & 573 & 30.0 \\
\hline
\end{tabular}

\section{3-2 Results and Discussion}

Fig.7 (a) and (b) demonstrates the evolution of the fire spread in the array of the buildings, where (a) and (b) are the results of $U_{\infty}=0.0$ and $5.0\left[\mathrm{~m} \cdot \mathrm{s}^{-1}\right]$, respectively. The dark color 
indicates the compartments at high temperatures. However, the dark color turns back to light color after the fire load has consumed and the temperature dropped.

For both cases, the fire spread readily after the ignition and developed to be an urban fire involving multiple building fires. For $U_{\infty}=0.0\left[\mathrm{~m} \cdot \mathrm{s}^{-1}\right]$, the fire spread symmetry to N-S axis and E-W axis due to the composition of rooms in the building. On the other hand, for $U_{\infty}=5.0\left[\mathrm{~m} \cdot \mathrm{s}^{-1}\right]$, the fire spread faster to the direction of North which was the down stream ward of the wind blowing. This is because the fire-induced plumes from the fire compartments were blown down by the wind and raised the ambient temperature of the downstream buildings. The fire spread to the upstream was faster when $U_{\infty}=0.0\left[\mathrm{~m} \cdot \mathrm{s}^{-1}\right]$ than $U_{\infty}=5.0\left[\mathrm{~m} \cdot \mathrm{s}^{-1}\right]$. The reason for this is that the heat released in the compartment was carried away by ventilation and currently no model for accelerating effect of combustion due to ventilation has been incorporated.

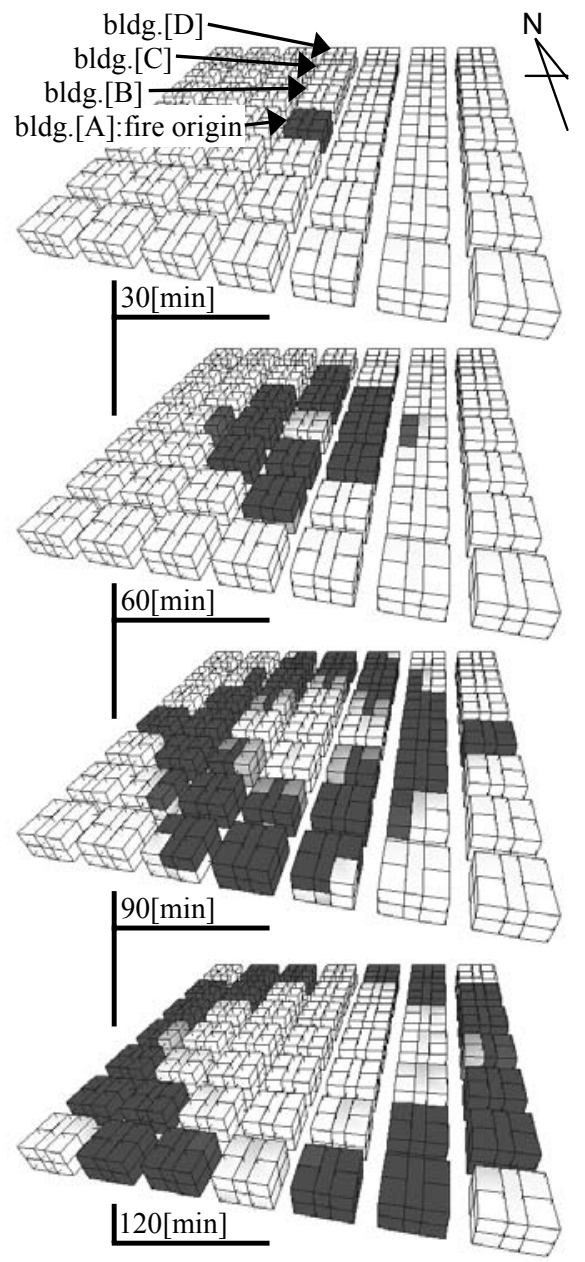

Fig. 7(a): $U_{\infty}=0.0\left[\mathrm{~m} \cdot \mathrm{s}^{-1}\right]$

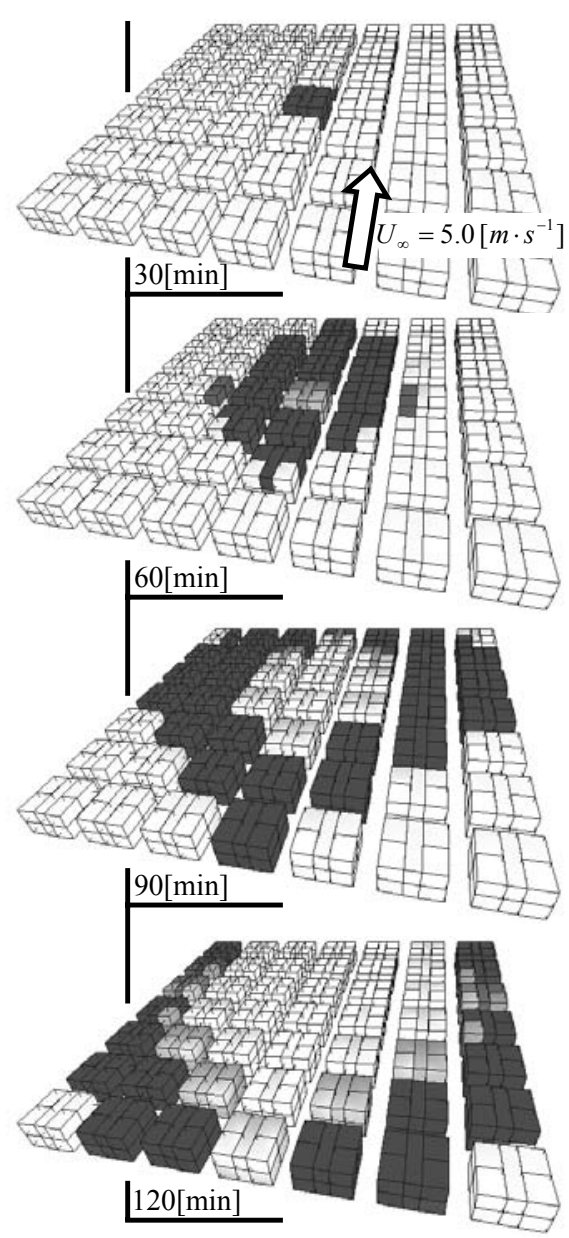

Fig. 7(b): $U_{\infty}=5.0\left[\mathrm{~m} \cdot \mathrm{s}^{-1}\right]$ 
Fig. 8 shows the compartment gas temperature change in the buildings $[\mathrm{A}],[\mathrm{B}],[\mathrm{C}]$ and [D] which are indicated in Fig.7. Solid line indicates the temperature transition of the compartments No.1s ( $1^{\text {st }}$ floor) and dotted line indicates the ones of the compartments No.6s ( $2^{\text {nd }}$ floor). As shown, the fire successively spread from one building to another.

Except for building [A], which was the origin of the fire, the temperature followed the similar change. This is due to the array of the buildings that were uniform in distance and consequently the external heating conditions were similar.

For both cases, the growth rates of fire in the $2^{\text {nd }}$ floor compartments were faster than that of the $1^{\text {st }}$ floor. There are two reasons: (1) the heat generated in the $1^{\text {st }}$ floor compartment fire was transported to the $2^{\text {nd }}$ floor by buoyancy and; (2) $2^{\text {nd }}$ floor compartments were closer to the plume center-lines and exposed to more severe heating by plumes.

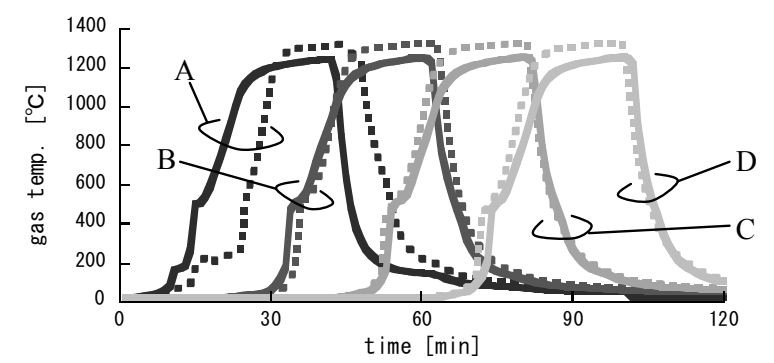

Fig. 8(a): Gas temp. of bldg.[A] [D] at $U_{\infty}=0.0\left[\mathrm{~m} \cdot \mathrm{s}^{-1}\right]$ (solid: No.1, dotted: No.6)

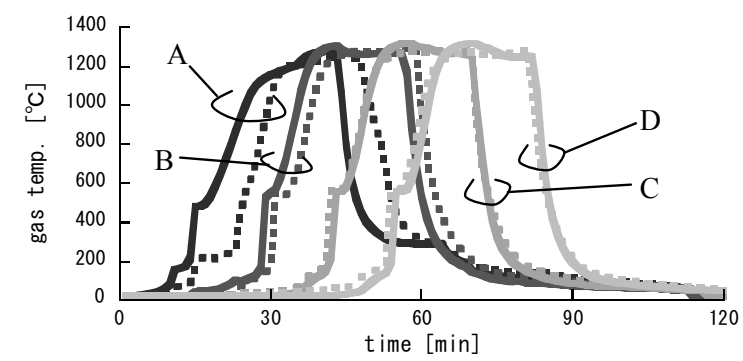

Fig. 8(b): Gas temp. of bldg.[A] [D] at $U_{\infty}=5.0\left[\mathrm{~m} \cdot \mathrm{s}^{-1}\right]$ (solid: No.1, dotted: No.6)

\section{CONCLUSIONS}

A physically-based model for predicting the urban fire spread is addressed. The model was applied to the ideal urban district and the building-to-building fire spread was simulated. However, the model is still at the exploratory stage and before placing the model for the practical use of evaluating the losses due to post-earthquake fires, refinements should be made. Yet, judging from the results of its application to an ideal urban configuration, it is considered that the model is in a right direction, which is encouraging for further development. 


\section{REFERENCE}

[1] Hamada M.: "On the Rate of Fire Spread”, Study of Disasters, vol.1 (1951)

[2] Horiuchi S.: "Fire Protection of Buildings" (1973)

[3] Tokyo Fire Station: "Resolutions and Measures to Post-Earthquake Fires" (1985)

[4] Itoigawa E., Iwami T., Kaji T., Kawanaka T., Kumagai Y. Tukagoshi I. and Masuyama T.: "Study of Real Time System for Information Processing of Post-earthquake Fire -Fire Spread Prediction and Evacuation Control-“, Report of the BRI, No.120 (1989)

[5] Quintiere J.: “A Simplified Theory for Generalizing Results from a Radiant Panel Rate of Flame Spread Apparatus", Fire and Materials, Vol.5 No.2 (1981)

[6] Yokoi S.: "Study on the Prevention of Fire Spread Caused by Hot Upward Current", Report of the BRI, No.34 (1960)

[7] Recommendation for Fire Resistant Design of Steel Structures, AIJ (1999)

[8] Beyler C. L.: "Fire Plumes and Ceiling Jet", Fire Safety Journal, Vol.11, pp53-76 (1986)

[9] Yokoi S.: "Temperature Distribution in the Down Stream of a Line Heat Source", Study of Disasters, Vol.8 (1970)

[10] Tsuchihashi T. et al.: "Estimation of the Rising Temperature at the Heated Points by the Fire Plume of Two Fire Sources", Proceedings of the annual AIJ meeting, A-2, pp13-14 (2000)

[11] Aburano, K. et al.: "Survey and Analysis on Surface Area of Fire Load", Fire Science and technology, Vol. 19, No. 1, pp11-25 (1999)

\section{NOMENCLATURE}

\section{Alphabets}

\begin{tabular}{|c|c|}
\hline$A$ & area $\left[\mathrm{m}^{2}\right]$ \\
\hline$c_{P}$ & specific heat $\left[\mathrm{kJ} \cdot \mathrm{kg}^{-1} \cdot \mathrm{K}^{-1}\right]$ \\
\hline$g$ & acceleration due to gravity $\left[\mathrm{m} \cdot \mathrm{s}^{-2}\right.$ \\
\hline$h$ & $\begin{array}{l}\text { convective heat transfer } \\
\text { coefficient }\left[\mathrm{kW} \cdot \mathrm{m}^{-2} \cdot \mathrm{K}^{-1}\right]\end{array}$ \\
\hline$\Delta H$ & heat of combustion $\left[\mathrm{kJ} \cdot \mathrm{kg}^{-1}\right]$ \\
\hline$L$ & heat of gasification $\left[\mathrm{kJ} \cdot \mathrm{kg}^{-1}\right]$ \\
\hline$m$ & mass flow rate $\left[\mathrm{kg} \cdot \mathrm{s}^{-1}\right]$ \\
\hline$\dot{m}_{B}$ & mass burning rate $\left[\mathrm{kg} \cdot \mathrm{s}^{-1}\right]$ \\
\hline$\dot{q}^{\prime \prime}$ & heat flux $\left[\mathrm{kW} \cdot \mathrm{m}^{-2}\right]$ \\
\hline$Q_{C}$ & $\mathrm{HRR}[\mathrm{kW}]$ \\
\hline$\dot{Q}_{D}$ & heat loss to openings $[\mathrm{kW}]$ \\
\hline$\dot{Q}_{W}$ & heat loss to wall $[\mathrm{kW}]$ \\
\hline$r$ & $\operatorname{radius}[\mathrm{m}]$ \\
\hline$T$ & temperature $[\mathrm{K}]$ \\
\hline$\Delta T$ & temperature rise $[\mathrm{K}]$ \\
\hline$U_{0}$ & wind velocity $\left[\mathrm{m} \cdot \mathrm{s}^{-1}\right]$ \\
\hline & compartment volume $\left[\mathrm{m}^{3}\right]$ \\
\hline & mass fraction[-] \\
\hline
\end{tabular}

\section{Greeks}

$\varepsilon \quad$ absorptivity, emissivity[-]

$\phi \quad$ char fraction[-]

$\varphi_{R} \quad$ configuration factor[-]

$\dot{\Gamma} \quad$ consumption rate $\left[\mathrm{kg} \cdot \mathrm{s}^{-1}\right]$

$\theta \quad$ rise angle of plume[rad]

$\Theta \quad$ dimensionless temperature[-]

$\rho \quad$ gas density $\left[\mathrm{kg} \cdot \mathrm{m}^{-3}\right]$

$\sigma \quad$ Stefan-Boltzmann constant $\left[\mathrm{kW} \cdot \mathrm{m}^{-2} \cdot \mathrm{K}^{-4}\right]$

\section{Subscripts}

cr critical

$D \quad$ opening

Eflame ejected flame

$F \quad$ fuel or combustibles gas

$G$ opening material

$O$ oxygen

$P \quad$ pyrolysis of fuel

$W \quad$ wall 